\title{
Possibility of Using Entropy Method to Evaluate the Distracting Effect of Mobile Phones on Pedestrians
}

\author{
Nurul Retno Nurwulan * and Bernard C. Jiang \\ Department of Industrial Management, National Taiwan University of Science and Technology, \\ Taipei City 10607, Taiwan; bcjiang@mail.ntust.edu.tw \\ * Correspondence: nurul.retno@gmail.com; Tel.: +886-9-8422-2447 \\ Academic Editor: Anne Humeau-Heurtier \\ Received: 7 September 2016; Accepted: 28 October 2016; Published: 4 November 2016
}

\begin{abstract}
The number of mobile phone users keeps increasing every year and mobile phones have become a primary need for most people. Ordinarily, people are not aware of the risk from a common dual-task study, such as using a mobile phone while walking or simply standing. This study reviewed the methodology in evaluating the distracting effect of mobile phones on pedestrians. A comprehensive review of literature revealed that the most common method in quantifying pedestrian performance is to evaluate postural task performance. Since using a mobile phone while crossing the road is a type of dual-task study, it would give more clarity to investigate it using entropy methods that have been proven more sensitive than the traditional center of pressure (COP) in discriminating the changes in human balance. The descriptions of commonly used entropy methods were also given in order to give a broad overview of the possibility in applying the methods to further clarify the distracting effect of mobile phones.
\end{abstract}

Keywords: mobile phone; walking; standing; pedestrian; dual-task; entropy

\section{Introduction}

Mobile phones are considered a very crucial part of our daily lives. Some people carry more than one mobile phone for different purposes, such as for personal and business use. For efficiency reasons, most people often use a mobile phone when performing another activity. This is a common example of a dual-task activity that we frequently do anywhere, including when we are crossing the street. Previous study has shown that pedestrians' behaviors are considered to be a factor in pedestrians' injuries, based on the data from police departments [1]. Mobile phones used by pedestrians increase distractions while walking, putting pedestrian at a greater risk for accidents [2-5] because they have an impact on working memory [6].

Various studies have evaluated the distracting effect of mobile phones on pedestrians by analyzing historical data, observations, and experiments either on the road or in the laboratory. It is undeniable that mobile phones impair the pedestrian's performance in crossing the road, because pedestrians tend to pay attention to the phone instead of the road. However, most pedestrians are considered to be expert users of mobile phones considering the majority pedestrians are young adults. Young adults have good adaptability in adjusting their movements to maintain balance in the perturbed environment. Therefore, the conclusion about how distracting using a mobile phone is on balance remains unclear.

Dynamical system analyses have been adapted in the fields of biology and medicine to help further clarify the regulatory processes that enable humans to function and adapt to the environment. Entropy methods have been used to quantify the amount of information in human balance signals for studying the center of pressure (COP) dynamics [7-10]. They have received a significant amount of attention due to their sensitivity in determining the regularity and complexity of the signals. 
This study reviewed the methodology of analyzing the pedestrians distracted by mobile phones. With regard to the sensitivity of the entropy methods in detecting the changes in human balance signals, the aim of this study was to give a brief review of the possibility of using entropy methods to clarify the distracting effect of mobile phones on human balance.

\section{Methods}

We performed a systematic review of publications evaluating the methods used to measure the distracting effect of mobile phone use on human balance. The electronic databases Science Direct, ISI Web of Science, Emerald Group Publishing, Springer Journal Database were searched. The following terms were used in the search strategy: "balance", "center of pressure", "distraction", "dual-task activity", "gait", "mobile phone", "postural control", "posture", "texting", and "walking". This returned 92 unique results. Articles were excluded if (1) they were not written in English; (2) they were not original research; and (3) they did not use experimentation as the evaluation method. Only the experiment-based studies were included as part of this review. The studies based on observational and historical data were not considered.

These considerations resulted in 66 articles. The review is divided into three parts. The first part reviews the methodology of the research studies on distracted pedestrians. The second part reviews the methodology of the research studies on postural stability. The third part reviews the entropy methods on postural stability studies.

\section{Results}

The initial step of the review was identifying the practical problems caused by mobile phone use in daily life. There have been previous studies evaluating the distracting effect of mobile phone use on pedestrians. These studies were conducted by doing the experiment on the road and/or conducting simulations in the laboratory. Those studies mostly used postural task performance as their evaluation method. With regard to this, the next step was reviewing the research studies on postural stability. Multiscale entropy (MSE) has been increasingly used to evaluate the relationship between complexity and the physiological system, such as heart rate and gait dynamics, due to its sensitivity.

\subsection{Research Studies on Distracted Pedestrians}

This section comprehensively reviews the studies on pedestrians distracted by mobile phones. The main focus of this section is to determine the methodology used by the previous studies to quantify the distracting effect of mobile phones on pedestrians. The findings of this section are crucial in revealing how effective the methods are in quantifying mobile phone distraction. With regard to this, only the experiment-based studies were reviewed.

The review results show that all of the studies tried to evaluate the effect of mobile phones' features that were considered to distract the users' attention while performing postural tasks, such as standing or walking. Phoning is considered to be more distracting than listening to music. Pedestrians missed more crossing opportunities when engaged in phone conversations compared to listening to music. This might happen because phone conversations require more attention with the subjects needing to listen and respond to questions, while listening to music is a passive disturbance with no content-related demand [4]. However, a study by Schwebel et al. showed that listening to music is more distracting than phoning, regardless of the fact that listening to music requires less cognitive complexity [11]. Phoning is considered to be as distracting as a mental task [5], but less distracting than texting. The subjects walked slower and had shorter strides while performing walking and texting [12]. Texting involves reading and typing, which is more cognitively demanding than talking [11]. Similar to texting, replying to emails and gaming also require cognitive attention that may take a serious toll on safe pedestrian behavior $[13,14]$. 
The studies are classified by the methods used to measure the distracting effect of mobile phone use on balance, as shown in Table 1. A concise explanation of the methods is provided in the following sub-sections.

\subsubsection{Success Rate of the Primary Task}

Pedestrians distracted by the mobile phone had poorer crossing performance. The distracted pedestrians tended to walk slower, were more likely miss the crossing opportunities, and were more likely to be hit or almost hit because they look at their mobile phones instead of around the street environment. Trial duration [4,5,11,13], success rate [4], time-out rate [4,11], missed opportunities [5,11,13], attention to traffic $[5,11,13]$, and hits/close calls $[4,5,11,13]$ were the parameters used in quantifying the performance of pedestrians when crossing the street.

Neider et al. investigated the effect of distracted attention while crossing a busy street. Pedestrians conversing on the phone were less likely to recognize and act on crossing opportunities compared to those listening to music [4]. Stavrinos et al. found that phoning is as distracting as spatial and arithmetic tasks. However, phoning did not affect the attention to traffic [5]. In order to investigate which phone feature is the most distracting, Schwebel et al. compared the distractions from phoning, texting, and listening to music on pedestrian performance. The study found that listening to music and texting caused more hits [11]. Byington and Schwebel evaluated the other mobile phone features' distracting effects on crossing the road. When distracted, the pedestrian waited longer to cross, missed more crossing opportunities, took longer to initiate crossing, looked left and right less, spent more time looking away from the road, and was more likely to be hit or almost hit [13].

\subsubsection{Primary Task Performance}

Posture and gait performance are the most common parameters in measuring the distracting effect of mobile phones. The effect of the phone on static posture might not be as serious as it is on a subject's gait. However, it is still important to understand the motor mechanism during unperturbed and perturbed conditions. Center of pressure (COP) is the common approach to characterize postural control and to understand the motor mechanism. The mean distance, total excursion, mean velocity, and sway area are the common parameters. Nurwulan et al. used the entropy-based method along with the COP method to measure the effect of mobile phones on the static posture. To evaluate the effect on the dynamic posture, they compared the reaching distances with and without a secondary task [15].

Measuring gait performance might be a better approach to evaluate the distracting effect than posture, since it depicts a real situation. The common parameters in the reviewed studies are: gait phase [16], gait velocity [6,16], gait speed [14,17-19], gait cycle [17], cadence [12,14,17,18], stride velocity [12], stride time [12,14,17], stride length $[12,14,17,18,20]$, step time $[14,17,21]$, step length $[14,17,21,22]$, single support [17], and double support $[17,18,22]$. Other than the common parameters, the reviewed studies also used the other gait parameters: range of motion [20,23], local stability and margin of stability [21]. Regardless of the methods used in measuring the distraction effect of mobile phones, previous studies showed that the divided attention caused by mobile phones diminished the primary task performances.

\subsubsection{Secondary Task Performance}

Most studies focused on the effect of mobile phones on the posture and gait performance. However, there are also studies measuring the performance of secondary tasks such as texting speed and texting accuracy $[19,24]$, determining how the effects of sitting, standing, and walking impacted the pedestrians' ability to perform texting. Performing texting while walking decreased the texting speed and texting accuracy [19], while the study on expert typists on mobile phones showed walking significantly affected the experts' typing speeds, but did not affect the experts' accuracy rates [24]. 
Table 1. Systematic review of distracting effect of mobile phones on human balance.

\begin{tabular}{|c|c|c|c|}
\hline Authors & Methods & Measurements & Findings \\
\hline Nasar et al., 2008. & $\begin{array}{l}\text { Primary task: walking. Secondary } \\
\text { task: phoning }\end{array}$ & $\begin{array}{l}\text { Situation awareness task by putting random } \\
\text { objects along the walking route }\end{array}$ & $\begin{array}{l}\text { Pedestrians noticed more objects in the } \\
\text { no-phoning condition. }\end{array}$ \\
\hline Neider et al., 2010. & $\begin{array}{l}\text { Primary task: crossing the street in a virtual } \\
\text { reality environment. Secondary task: } \\
\text { listening to music, phoning }\end{array}$ & $\begin{array}{l}\text { Trial duration, success rate, collision rate, } \\
\text { time-out rate }\end{array}$ & $\begin{array}{l}\text { Phoning was more distracting than listening to music, } \\
\text { pedestrians were less likely to recognize and act on } \\
\text { crossing opportunities. }\end{array}$ \\
\hline Stavrinos et al., 2011. & $\begin{array}{l}\text { Primary task: crossing in a virtual } \\
\text { environment. Secondary task 1: phoning. } \\
\text { Secondary task 2: phoning, spatial task, } \\
\text { arithmetic task }\end{array}$ & $\begin{array}{l}\text { Time left to spare, missed crossing } \\
\text { opportunities, attention to traffic, } \\
\text { hits/close calls }\end{array}$ & $\begin{array}{l}\text { Pedestrians left less time to spare, missed more crossing } \\
\text { opportunities, and hit or almost hit when phoning. } \\
\text { However, phoning did not affect the attention to traffic. } \\
\text { Phoning is as distracting as the spatial and arithmetic tasks. }\end{array}$ \\
\hline $\begin{array}{l}\text { Lamberg and } \\
\text { Muratori, } 2012 .\end{array}$ & $\begin{array}{l}\text { Primary task: walking. Secondary task: } \\
\text { phoning, texting }\end{array}$ & $\begin{array}{l}\text { Linear distance, lateral deviation, } \\
\text { gait velocity }\end{array}$ & $\begin{array}{l}\text { Phoning and texting reduced gait velocity. Texting } \\
\text { increased lateral deviation and linear distance traveled. } \\
\text { Texting increased greater disruption in gait than phoning. }\end{array}$ \\
\hline Schwebel et al., 2012. & $\begin{array}{l}\text { Primary task: crossing in a virtual } \\
\text { environment. Secondary task: listening to } \\
\text { music, phoning, texting }\end{array}$ & $\begin{array}{l}\text { Time left to spare, look left and right, look } \\
\text { away, hits/close calls, missed opportunities }\end{array}$ & $\begin{array}{l}\text { Listening to music and texting while crossing caused } \\
\text { more hits. }\end{array}$ \\
\hline $\begin{array}{c}\text { Byington \& } \\
\text { Schwebel, } 2013 .\end{array}$ & $\begin{array}{l}\text { Primary task: crossing in a virtual } \\
\text { environment. Secondary task: read and } \\
\text { reply to email on the phone }\end{array}$ & $\begin{array}{l}\text { Hits/close calls, start delay, wait time, } \\
\text { missed opportunities, looks at traffic, eyes } \\
\text { off road }\end{array}$ & $\begin{array}{l}\text { When distracted, pedestrians waited longer to cross, missed } \\
\text { more crossing opportunities, took longer to initiate crossing, } \\
\text { looked left and right less, spent more time looking away } \\
\text { from the road, and were more likely to be hit or almost hit. }\end{array}$ \\
\hline Music et al., 2013. & $\begin{array}{l}\text { Primary task: standing still and walking. } \\
\text { Secondary task: Looking at the phone screen }\end{array}$ & Gait phase, gait velocity & $\begin{array}{l}\text { Gait velocity changed when participants paid more } \\
\text { attention to the phone screen. }\end{array}$ \\
\hline Clawson et al., 2014. & $\begin{array}{l}\text { Primary task: sitting, standing, and walking. } \\
\text { Secondary task: texting }\end{array}$ & Words per minute, accuracy & $\begin{array}{l}\text { Walking significantly affected the expert typing speeds but } \\
\text { did not affect the expert accuracy rates. }\end{array}$ \\
\hline Kim et al., 2014. & $\begin{array}{l}\text { Primary task: ramp ascent, ramp descent } \\
\text { walking. Secondary task: texting }\end{array}$ & $\begin{array}{l}\text { Gait speed, cadence, stride length, step } \\
\text { length, stride time, step time, gait cycle, } \\
\text { single support, double support }\end{array}$ & $\begin{array}{l}\text { Texting while walking decreased ramp gait speed, cadence, } \\
\text { stride length, step length, and single support, but increased } \\
\text { stride time, step time, gait cycle, and double support. }\end{array}$ \\
\hline Perlmutter et al., 2014. & $\begin{array}{l}\text { Primary task: walking. Secondary task: } \\
\text { phoning, texting }\end{array}$ & $\begin{array}{l}\text { Stride time, stride length, stride velocity, } \\
\text { cadence }\end{array}$ & $\begin{array}{l}\text { Participants walked slowly and had shorter strides while } \\
\text { performing texting. }\end{array}$ \\
\hline Schabrun et al., 2014 & $\begin{array}{l}\text { Primary task: walking. Secondary task: } \\
\text { texting on mobile phone }\end{array}$ & $\begin{array}{l}\text { Foot position, walking speed, range of } \\
\text { motion (ROM) }\end{array}$ & Slower walking while writing text. \\
\hline
\end{tabular}


Table 1. Cont.

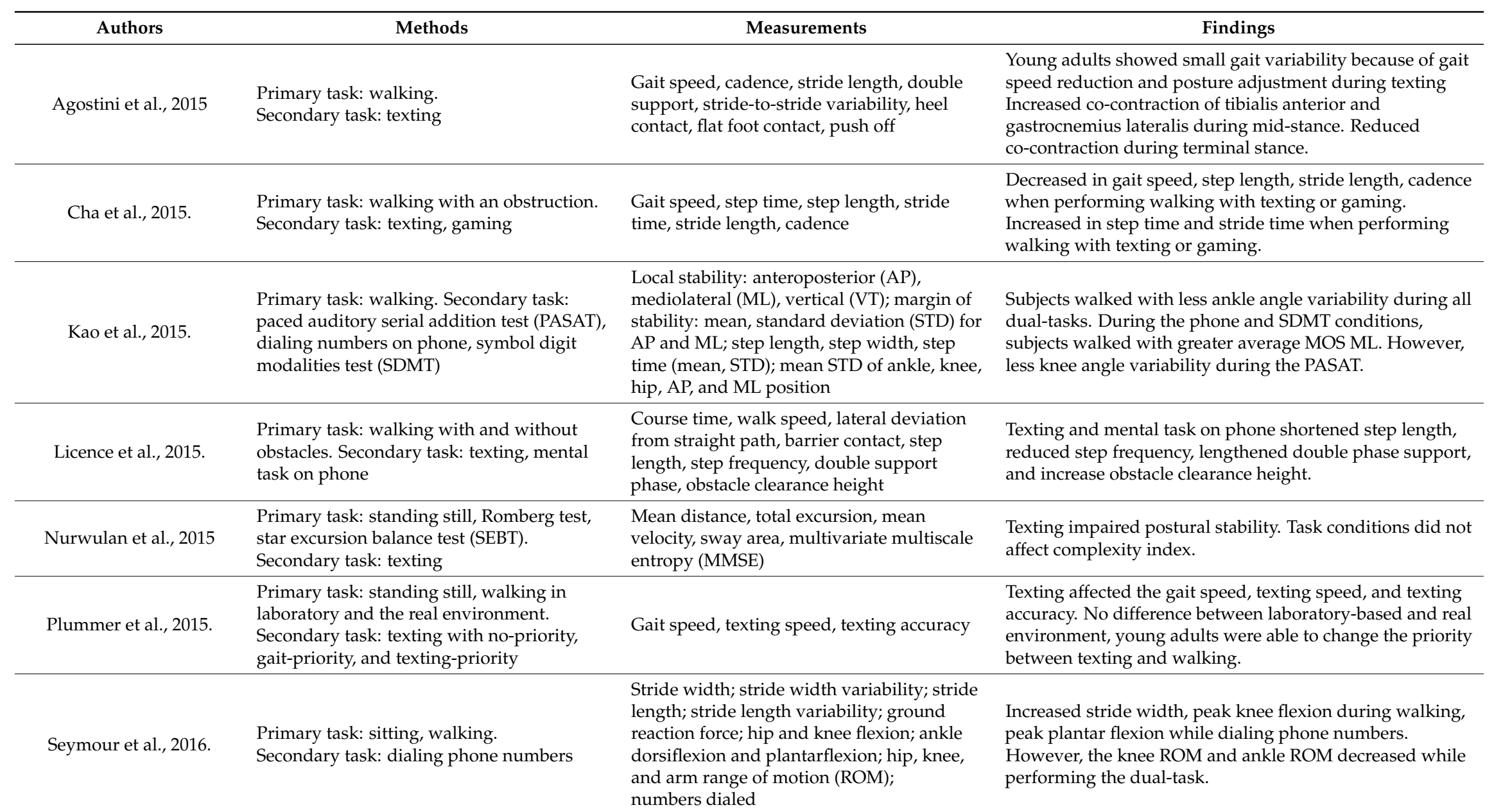




\subsubsection{Situation Awareness}

Nasar et al. used the situational awareness task to measure the distracting effect. The pedestrians were asked to perform walking and walking with phoning in an environment with objects planted along the route. The studies showed that the pedestrians recalled fewer objects in the phoning condition.

\subsection{Research Studies on Postural Stability}

Using a mobile phone while crossing the road is an example of a dual task with respect to postural stability. The pedestrians need to divide their attention between looking at the phone and the road. Postural stability has been studied in various ways with a range of different measures. The most typical measure of postural stability is the center of pressure (COP) because it can be obtained from a force platform directly [25]. COP is "the position of the applied force vector that is influenced by the shear forces produced by body segment accelerations" [25].

\subsubsection{Previous Studies on Postural Stability}

Postural stability studies are mostly linked to the dual-task study with postural balance as the primary task and another activity as the secondary task. Previous studies have extensively evaluated various kinds of secondary tasks such as cognitive load [26-32], physical load [33-35], visual load [32,33,36-38], and auditory load [36,39,40].

Although mobile phones have become a primary need in our daily lives, the number of studies on using mobile phones as a secondary task in postural stability studies is still limited. Previous studies regarding the distracting effect of mobile phones mostly did not consider their effect on postural stability. Specific studies related to mobile phones evaluated the effect of radio frequency radiation from the phone [39], using email functions [41], and texting [23] on postural stability.

\subsubsection{Postural Stability Measurements}

Measurements are often taken for granted, and people sometimes do not appreciate the importance of measurements. The right measurement will give us a picture of what is actually going on. Mostly, postural stability studies used the traditional COP as a measurement.

\section{Traditional Center of Pressure}

The signal of the COP has a bivariate distribution and is defined by ML (medio-lateral, $x$-axis) and AP (antero-posterior, y-axis). The COP is defined as the arithmetic means of $y_{0}(n)$ and $x_{0}(n)$.

$$
y(n)=y_{0}(n)-\bar{y}, x(n)=x_{0}(n)-\bar{x}
$$

where

$$
\bar{y}=\frac{1}{N} \sum y_{0}(n), \bar{x}=\frac{1}{N} \sum x_{0}(n), n=1, \ldots, N
$$

The COP stabilogram that is often used includes the mean resultant distance, total excursion, mean displacement velocity, sway area, 95\% confidence circle area, $95 \%$ confidence ellipse area, square root of the sum of the displacement variances in the $\mathrm{x}$ and $\mathrm{y}$ direction, and planar deviation.

This method has been widely used in postural stability studies due to its simplicity. However, the fact that the signal from the force platform is not linear and stationary makes the entropy-based methods become remarkable in measuring postural stability.

\section{Entropy-Based Methods}

Entropy is best known as a measure of uncertainty. It was first used in statistical mechanics to explain the thermodynamic behavior of large systems. Then it was introduced to the information theory field by Shannon in 1948 and has been developed and widely used in many different fields 
ever since. Entropy methods quantify the amount of information, complexity and regularity within a physiological signal, and have shown the ability to help in clarifying the underlying motor control mechanism between quiet standing and fall history. Entropy methods can be classified as state entropy and sequence entropy. State entropy quantifies the amount of information within the signal, while sequence entropy examines the repetition of the patterns of the signal.

Shannon entropy (ShanEn) is often stated to be the origin of the mutual information measure used in multi-modality medical image co-registration. It evaluates the repetition of certain states within a signal by measuring the probability of the signal occupying discrete states [42]. Since it was first introduced, the original ShanEn has been extended into many alternative forms of entropy methods. Renyi entropy (RenyEn) is the extension of ShanEn in a continuous form of the entropy method. Both Shannon and Renyi entropy are of the form of state entropy. This type of entropy method examines the frequency throughout the signal without considering its path [9].

The entropy methods that are commonly used nowadays are classified by sequence entropy type, derived from approximate entropy (ApEn). Sequence entropy methods examine the frequency of a series of values by evaluating the probability that particular values occur within a signal, considering the repetition of paths. The sequence entropy methods are approximate entropy (ApEn), sample entropy (SampEn), multiscale entropy (MSE), composite multiscale entropy (CMSE), and multivariate multiscale entropy (MMSE). ApEn was introduced as the practical application of Kolmogorov-Sinai (K-S) entropy [43]. It can be used for signals containing noise with relatively short data lengths. The advantage of using ApEn over mean and variance in statistical analysis is the ability to distinguish between two time series.

$$
\begin{gathered}
S=\left\{x_{t k}, k=1, \ldots, K\right\} \\
t k=k \times T
\end{gathered}
$$

where $\mathrm{S}$ is the discrete time, $\mathrm{x}_{\mathrm{tk}}$ is the signal value at a specific time, $\mathrm{k}$ is the number of samples, and $\mathrm{T}$ is the sampling period. Pattern $P_{m}(i)=\left\{x_{i}, x_{i+1}, \ldots, x_{i+m-1}\right\}$ is the sequence of $\mathrm{m}$ samples. Two patterns, $P_{m}(i)$ and $P_{m}(j)$, are considered similar if the difference is less than the tolerance $r$. If $\left|x_{i+k}-x_{j+k}\right|$ for $0 \leq k \leq m$, then:

$$
C_{i}^{m}(r)=\frac{n_{i m}(r)}{N-m+1}
$$

where $n_{i m}(r)$ is the number of patterns in $P_{m}$ that are similar to $P_{m}(i), C_{i m}(r)$ is the fraction that resembles the pattern of the same length, and $m$ is the length of the pattern in $S$.

$$
\operatorname{ApEn}(S, m, r)=\ln \frac{C_{m}(r)}{C_{m+1}(r)}
$$

SampEn was developed to reduce the effects of sample length in ApEn by eliminating self-matches [44]. The complexity values obtained from ApEn and SampEn are limited to the time scale used in the sampling frequency. SampEn is basically the modified version of ApEn obtained by eliminating self-similar patterns.

$$
\text { SampEn }=-\log \frac{A_{m}}{B_{m-1}}
$$

where $A_{m}$ is the number of matches of length $m$ and $B_{m-1}$ is the number of matches of length $m$, excluding the end of the time series.

MSE calculates the SampEn across multiple time scales $(\tau)$ through a coarse-graining procedure to address multiple characteristic time scales. The length of the coarse-grained time series is reduced by the factor of $\tau$ which insulates the record length sensitivities of ApEn and SampEn in a shorter time series. For a given one-dimensional time series $x=\left\{x_{1}, x_{2}, \ldots, x_{n}\right\}$, the coarse-grained time series for a scale factor $\tau$ is obtained by averaging the consecutive $\tau$ numbers of data points in non-overlapping windows through the time series. 


$$
\mathrm{y}_{j}^{(\tau)}=\frac{1}{\tau} \sum_{i=(j-1) \tau+1}^{j \tau} x_{i}
$$

CMSE tries to reduce the effect of shortening the time series due to the scale factor by using a moving average procedure to compute MSE in the time scale $\tau$, then take the mean value of MSE over the time series [45]. Meanwhile, the MMSE evaluates the structural complexity of multivariate systems by calculating the relative complexity of the multichannel signals through the plot of the multivariate sample entropy [46].

\subsection{Entropy Methods on Postural Stability}

Entropy methods have been used widely in the fields of biology and medicine to quantify the complexity of physiological time series. They have been proven to be able to discriminate the healthy and disease conditions $[43,44]$. Due to the nonlinear nature of physiological systems, the traditional linear time-domain and frequency-domain methods cannot fully describe the interactions of the highly complex physiological systems. Thus, advanced nonlinear methods are better in detecting the changes in the human body.

\subsubsection{Previous Studies Based on the Postural Tasks}

Previous entropy studies, as shown in Table 2, evaluated the effect of dual tasks on postural stability with respect to either static or dynamic postural stability. Quiet standing is the most common postural task in the postural stability studies [9,15,47-62]. The other static postural tasks, such as the single-leg stance [59,63], tandem stance [15], and standing on a sway support $[52,55,60]$, were used to evaluate the performance of the perturbed balance task. Only a few studies used the dynamic postural stability, such as walking [61,64].

\subsubsection{Comparison between Entropy Methods and Traditional COP}

The studies that evaluated static postural stability used various entropy methods, such as Shannon entropy [9,62], Renyi entropy [9,62], approximate entropy [47,51,54,62], sample entropy [51,54,55,62,63], multiscale entropy [48-50,53,56-59,61,62,65], composite multiscale entropy [62], and multivariate multiscale entropy $[15,56]$, in order to find a better approach to evaluate human posture. The findings of the previous studies comparing entropy and traditional COP methods suggested that the entropy approach is more sensitive in characterizing sway [59] and gives higher reliability [55].

\subsubsection{Entropy Methods Comparison}

Entropy methods have been proven as more effective and clearer than the traditional COP method. However, there are various kinds of entropy methods that can be used to evaluate human postural stability. Each method has its evaluations and interpretation of the results. Which method is the most sensitive in analyzing the human posture remains unclear. To address this issue, several studies tried to compare two or more entropy methods that have been widely used.

Gao et al. used Shannon and Renyi entropy to investigate the effect of mild traumatic brain injury on postural stability. The Shannon entropy value increased with data length, but the value was smaller compared to the shorter data length. Thus, it is not appropriate to associate the value of ShanEn with the complexity of postural sway on short data. In order to analyze the postural sway, the appropriate data length is important. Shannon entropy (ShanEn) varies with data length, similar to the behavior of approximate entropy (ApEn), while the Renyi entropy (RenyEn) method showed a general trend in relation to the postural sway. The variation of the RenyEn value was rather complicated, indicating the subjects might not have fully recovered. The other postural stability studies compared ApEn and sample entropy (SampEn) to analyze the postural sway [51,54]. ApEn is the least robust to sampling frequency and noise manipulations. It exhibited U-patterns when adding noise to the COP signal [51]. 
Table 2. Systematic review of previous postural stability studies using entropy methods.

\begin{tabular}{|c|c|c|c|}
\hline Authors & Methods & Measurements & Findings \\
\hline Sabatini, 2000 & $\begin{array}{l}\text { Primary task: standing still. } \\
\text { Secondary task: visual conditions } \\
\text { (eyes open and eyes closed) }\end{array}$ & $\begin{array}{l}\text { Romberg's test parameters, approximate } \\
\text { entropy (ApEn), singular value spectrum } \\
\text { entropy (SVSE), spectral entropy (SE) }\end{array}$ & $\begin{array}{l}\text { Visual conditions did not affect postural stability in ML axis of } \\
\text { young adults. Uncertainty of the relevance from clinical view point } \\
\text { in using entropy-based measurements compared to Romberg's } \\
\text { test parameters. }\end{array}$ \\
\hline Costa et al., 2003 & $\begin{array}{l}\text { Normal walk, slow pace walk, fast } \\
\text { pace walk, walk into a metronome }\end{array}$ & Multiscale entropy (MSE) of stride interval & Normal walk has the highest complexity index (CI). \\
\hline Kang et al., 2009 & $\begin{array}{l}\text { Primary task: barefoot quiet } \\
\text { standing. Secondary task: } \\
\text { counting backwards }\end{array}$ & $\begin{array}{l}\mathrm{COP} \text { (Root-mean-square sway, COP path } \\
\text { length, mean power frequency); MSE }\end{array}$ & $\begin{array}{l}\text { Older adults were categorized as } 38 \% \text { pre-frail and } 9 \% \text { were frail. } \\
\mathrm{CI} \text { in the AP direction was lower in pre-frail and frail subjects } \\
\text { compared to non-frail subjects. Lower CI in the dual task. }\end{array}$ \\
\hline Manor et al., 2010 & $\begin{array}{l}\text { Primary task: barefoot quiet- } \\
\text { standing Secondary task: } \\
\text { counting backwards }\end{array}$ & COP (sway area, speed); MSE & $\begin{array}{l}\text { The CI was higher in the control group during the quiet standing. } \\
\text { Dual-tasking increased COP speed and sway area but reduced CI. }\end{array}$ \\
\hline Gao et al., 2011 & $\begin{array}{l}\text { Injured athletes performed } \\
\text { standing still }\end{array}$ & $\begin{array}{l}\text { Shannon entropy (ShanEn), Renyi } \\
\text { entropy (RenyEn) }\end{array}$ & $\begin{array}{l}\text { ShanEn and RenyEn values decreased after concussion. } \\
\text { Entropy-based methods were effective in detecting postural } \\
\text { instability long after concussion and able to determine the optimal } \\
\text { length of time series. }\end{array}$ \\
\hline Gruber et al., 2011 & Quiet standing & $\begin{array}{l}\text { COP (range, velocity, acceleration, sway } \\
\text { area); Time-to-contact; MSE }\end{array}$ & $\begin{array}{l}\text { Adolescent idiopathic scoliosis patients showed greater COP sway in } \\
\text { ML direction, less time-to-contact, and lower CI. }\end{array}$ \\
\hline Rhea et al., 2011 & Standing still & $\begin{array}{l}\text { ApEn, sample entropy (SampEn), recurrence } \\
\text { quantification analysis entropy (RQAEn) }\end{array}$ & $\begin{array}{l}\text { The ApEn exhibited U patterns when adding noise to COP signal, } \\
\text { while SampEn value increased and RQAEn decreased. Significant } \\
\text { differences in SampEn values between different frequencies both in } \\
\text { COP signal and COP signal with added noise. ApEn is the least } \\
\text { robust to sampling frequency and noise manipulations. }\end{array}$ \\
\hline Wei et al., 2012 & $\begin{array}{l}\text { Quiet standing, quiet standing after } \\
\text { walk with vibratory shoes }\end{array}$ & $\begin{array}{l}\text { Empirical mode decomposition } \\
\text { (EMD)-enhanced MSE, Multivariate EMD } \\
\text { (MEMD)-enhanced Multivariate } \\
\text { MSE (MMSE) }\end{array}$ & $\begin{array}{l}\text { Lower CI after the use of vibration shoes. MEMD-enhanced MMSE } \\
\text { improvement is higher than EMD-enhanced MSE. }\end{array}$ \\
\hline Huang et al., 2013 & $\begin{array}{l}\text { Quiet standing eyes open and eyes } \\
\text { closed, standing on water pad with } \\
\text { eyes open and eyes closed }\end{array}$ & $\begin{array}{l}\text { EMD-enhanced MSE, MEMD-enhanced } \\
\text { MSE, MEMD-enhanced MMSE }\end{array}$ & $\begin{array}{l}\text { Lower CI in with water pad condition. The MEMD-enhanced MMSE } \\
\text { was able to distinguish the different sways clearer. }\end{array}$ \\
\hline Jiang et al., 2013 & $\begin{array}{l}\text { Condition } 1 \text { : standing still and dual } \\
\text { task. Condition 2: standing with } \\
\text { eyes open and eyes closed. } \\
\text { Condition 3: without and with } \\
\text { vibratory insoles }\end{array}$ & Traditional COP, MSE & $\begin{array}{l}\text { Significant differences between standing still and dual task, eyes } \\
\text { open and eyes closed, and with and without vibratory insoles using } \\
\text { MSE. COP data of elderly fallers were less complex than healthy } \\
\text { young subjects. Entropy-based methods can decompose COP data } \\
\text { into different frequency band using empirical mode decomposition } \\
\text { (EMD) in order to distinguish higher and lower frequency signals. } \\
\text { Age factor has more influence on higher frequency COP data. Sight } \\
\text { has more influence on lower frequency data. }\end{array}$ \\
\hline
\end{tabular}


Table 2. Cont

\begin{tabular}{|c|c|c|c|}
\hline Authors & Methods & Measurements & Findings \\
\hline Manor et al., 2013 & $\begin{array}{l}\text { Quiet standing before, during, and } \\
\text { after } 24 \text { weeks of Tai Chi training }\end{array}$ & COP (area, speed); MSE & The CI increased after 24 weeks of training sessions. \\
\hline Rigoldi et al., 2013 & $\begin{array}{l}\text { Primary task: standing still. } \\
\text { Secondary task: visual condition } \\
\text { (eyes open and eyes closed) }\end{array}$ & Traditional COP, ApEn, SampEn & $\begin{array}{l}\text { Subjects with illness had higher values in COP displacement. } \\
\text { No difference in COP frequency. Subjects with illness had lower } \\
\text { ApEn and SampEn values. }\end{array}$ \\
\hline Baltich et al., 2014 & $\begin{array}{l}\text { Standing with eyes open, standing } \\
\text { with eyes closed, standing on foam } \\
\text { with eyes open }\end{array}$ & $\begin{array}{l}\text { COP (excursion, path length, } 95 \% \text { ellipse } \\
\text { area); Entropic half-life [E(1/2)] of Sample } \\
\text { Entropy (SampEn) }\end{array}$ & $\begin{array}{l}\text { The COP movement was largest when standing with eyes closed. } \\
\mathrm{E}(1 / 2) \text { was the highest when standing on foam. } \mathrm{E}(1 / 2) \text { has } \\
\text { high reliability. }\end{array}$ \\
\hline Chen \& Jiang, 2014 & $\begin{array}{l}\text { Quiet standing before, during, and } \\
\text { after } 16 \text { weeks of training }\end{array}$ & COP (total distance), EMD, MSE, MMSE & $\begin{array}{l}\text { Beneficial effects of the training showed by the higher CI during and } \\
\text { after the training. }\end{array}$ \\
\hline Fournier et al., 2014 & Quiet standing & COP (range, velocity, $95 \%$ ellipse area); MSE & $\begin{array}{l}\text { Children with Autism spectrum disorder have larger fluctuations in } \\
\text { the COP data and less CI. }\end{array}$ \\
\hline Pau et al., 2014 & $\begin{array}{l}\text { Quiet standing before and after the } \\
\text { simulated firefighting and rescue } \\
\text { activities }\end{array}$ & COP (mean velocity, sway area); MSE & The CI reduced after the activity, career group had smaller reduction. \\
\hline Wayne et al., 2014 & $\begin{array}{l}\text { Quiet standing eyes open, quiet } \\
\text { standing eyes closed, single leg } \\
\text { stance (SLST), timed up and } \\
\text { go (TUG) }\end{array}$ & COP (sway velocity, elliptical area); MSE & $\begin{array}{l}\text { Tai Chi experts showed greater CI and greater sway. Tai Chi experts } \\
\text { performed longer SLST and faster TUG tasks. MSE is more sensitive } \\
\text { in characterizing sway during quiet standing. }\end{array}$ \\
\hline Yeh et al., 2014 & $\begin{array}{l}\text { Standing with the combinations of } \\
\text { eyes open or eyes closed with fixed } \\
\text { or sway surrounding and fixed or } \\
\text { sway support }\end{array}$ & MSE & $\begin{array}{l}\text { The CI for healthy elderly and dizzy/imbalance group was lower } \\
\text { than the healthy young group. }\end{array}$ \\
\hline Baltich et al., 2015 & Single leg stance & $\begin{array}{l}\mathrm{COP}(95 \% \text { ellipse area, path length, } \\
\text { excursion); } \mathrm{E}(1 / 2)\end{array}$ & Injured subjects exhibited greater excursion and higher CI. \\
\hline Decker et al., 2015 & $\begin{array}{l}6 \text { min walking distance test } \\
(6 \mathrm{MWD}) \text {, quiet standing barefoot }\end{array}$ & $\begin{array}{l}\text { COP (standard deviations, path length, } 90 \% \\
\text { ellipse area); SampEn, MSE }\end{array}$ & $\begin{array}{l}\text { Subjects with lower physical functions exhibited lower SampEn } \\
\text { values. Lower physical function is associated with lower complexity. }\end{array}$ \\
\hline Nurwulan et al., 2015 & $\begin{array}{l}\text { Standing still, Romberg test, SEBT } \\
\text { test.Secondary task: texting }\end{array}$ & $\begin{array}{l}\text { Mean distance, Total excursion, mean } \\
\text { velocity, sway area, multivariate multiscale } \\
\text { entropy (MMSE) }\end{array}$ & $\begin{array}{l}\text { Texting impaired postural stability. Task conditions did not affect } \\
\text { complexity index. }\end{array}$ \\
\hline Fino et al., 2016 & $\begin{array}{l}\text { Quiet standing with eyes open and } \\
\text { eyes closed }\end{array}$ & $\begin{array}{l}\text { COP (area, velocity, standard deviation); } \\
\text { approximate entropy (ApEn); SampEn; MSE; } \\
\text { composite MSE (CMSE); recurrence } \\
\text { quantification analysis entropy (RQAE); } \\
\text { Shannon entropy (ShanEn); Renyi } \\
\text { entropy (RenyEn) }\end{array}$ & The MSE and CMSE performed the best. \\
\hline
\end{tabular}


Since it was introduced by Ahmed and Mandic in 2011, multivariate multiscale entropy (MMSE) has gained special attention. Several studies investigated the sensitivity of multiscale entropy (MSE) and MMSE $[53,56,66]$. The results of the studies showed that MMSE is more sensitive to changes [66] and able to distinguish more subjects [52,56].

In 2016, Fino et al. tried to compare the discriminatory ability of ShanEn, RenyEn, ApEn, SampEn, MSE, and composite MSE (CMSE) in order to determine which entropy method is the most sensitive for distinguishing fallers and non-fallers. ShanEn and RenyEn were the worst in discriminating the fallers from the non-fallers. ShanEn and RenyEn measure the regularity of the signal, not the time series. Ultimately, MSE and CMSE showed the best ability to distinguish the fallers and non-fallers.

\section{Discussion and Conclusions}

This study reviewed the methodology in evaluating the distracting effect of mobile phones on human balance. The reviewed studies are in agreement that mobile phones impaired pedestrians' balance. The most common method in distracted pedestrian studies is to evaluate the performance of postural tasks. However, those studies did not consider the underlying effects of the environment on the motor mechanism that cause the impairment of postural stability. In summary, the study found the following points:

1. The issue of distracted pedestrians has become a phenomenon. Various studies have investigated the fatality of divided attention caused by mobile phones while crossing roads. They found that mobile phones significantly affect the performance of pedestrians, with respect to either the postural task or the secondary task performance.

2. Measuring the postural task performance is the most common approach to evaluate the distracting effect of mobile phones on pedestrians. This might be because divided attention may cause a fall or accident due to the poor postural task performance.

3. In the dual-task studies in relation to human postural stability, the center of pressure (COP) is the common method to characterize postural control and to understand the motor mechanism.

4. Due to the lack of clarity in the conclusion about postural sway as the predictor of balance, entropy methods have gained significant attention. Entropy methods have been proven for their ability in quantifying the complexity and regularity of the human postural signal compared to the traditional COP method.

5. Most entropy studies on postural stability investigated static postural stability. Only a few studies used entropy methods to evaluate dynamic postural stability, such as walking. This might be because it is easier to do the sensitivity evaluation of entropy methods on static postural stability. Nonetheless, entropy methods are able to quantify gait dynamics.

6. The sensitivity comparison among the most widely used entropy methods in postural stability showed that MSE, CMSE, and MMSE are the most reliable approaches in discriminating the changes in human balance.

Based upon the review presented in this study, there is a need for obtaining a more in-depth understanding of the divided attention of pedestrians while crossing the road. The previous studies in relation to pedestrian fatality came out with an agreement that mobile phones impaired the performance of the gait and posture, which may cause accidents. The COP methods and gait measurements are able to identify the differences between the unperturbed and perturbed environment. However, the underlying effect of the ever-changing environment on the motor control mechanism was not considered. Therefore, in order to get a thorough evaluation of the distracting effect of mobile phones on human balance, we recommend that future studies consider using entropy-based methods along with traditional parameters in order to obtain thorough information on how distracting the mobile phone is to balance and how well humans can adjust their motor control mechanism to maintain balance in the perturbed environment. 
As MSE has been widely used, it is practically safe to use MSE to measure entropy. CMSE and MMSE are modifications of the MSE algorithm used in order to obtain more reliable data that is representative of real situations; using either CMSE or MMSE would be more appropriate for future studies. Nevertheless, there is no study comparing the reliability of CMSE and MMSE in human balance, and using both methods with MSE as the baseline to analyze the complexity of human balance would contribute to a better understanding in postural stability studies.

Acknowledgments: This research was financially supported by the Ministry of Science and Technology (MOST) of Taiwan (MOST 102-2221-E-155-026-MY3).

Author Contributions: Nurul Retno Nurwulan and Bernard C. Jiang conceived and designed the experiments; Nurul R. Nurwulan performed the experiments; Nurul R. Nurwulan and Bernard C. Jiang analyzed the data; Nurul R. Nurwulan and Bernard C. Jiang contributed reagents/materials/analysis tools; Nurul R. Nurwulan wrote the paper. Both authors have read and approved the final manuscript.

Conflicts of Interest: The authors declare no conflict of interest.

\section{References}

1. Bungum, T.J; Day, C.; Henry, J. The association of distraction and caution displayed by pedestrian at lighted crosswalk. J. Community Health 2005, 30, 269-279. [CrossRef] [PubMed]

2. Hatfield, J.; Murphy, S. The effects of mobile phone use on pedestrian crossing behavior at signalised and unsignalised intersections. Accid. Anal. Prev. 2007, 39, 197-205. [CrossRef] [PubMed]

3. Nasar, J.; Hecht, P.; Wener, R. Mobile telephones, distracted attention, and pedestrian safety. Accid. Anal. Prev. 2008, 40, 69-75. [CrossRef] [PubMed]

4. Neider, M.B.; McCarley, J.S.; Crowell, J.A.; Laczmarski, H.; Kramer, A.F. Pedestrians, vehicles, and cell phones. Accid. Anal. Prev. 2010, 42, 589-594. [CrossRef] [PubMed]

5. Stavrinos, D.; Byington, K.W.; Schwebel, D.C. Distracted walking: Cell phones increase injury risk for college pedestrians. J. Saf. Res. 2011, 42, 101-107. [CrossRef] [PubMed]

6. Lamberg, E.M.; Muratori, L.M. Cell phones change the way we walk. Gait Posture 2012, 35, 688-690. [CrossRef] [PubMed]

7. Borg, F.G.; Laxaback, G. Entropy of balance-Some recent results. J. Neuroeng. Rehabil. 2010, 7, 38. [CrossRef] [PubMed]

8. Costa, M.; Priplata, D.; Lipsitz, L.; Wu, Z.; Huang, N.; Goldberger, A.; Peng, C.K. Noise and poise: Enhancement of postural complexity in the elderly with a stochastic-resonance-based therapy. Europhys. Lett. 2007, 77, 68008. [CrossRef] [PubMed]

9. Gao, J.; Hu, J.; Buckley, T.; White, K.; Hass, C. Shannon and Renyi entropies to classify effects of mild traumatic brain injury on postural sway. PLoS ONE 2011, 6, e24446. [CrossRef] [PubMed]

10. Morrison, S.; Colberg, S.E.; Parson, H.K.; Vinik, A.I. Relation between risk of falling and postural sway complexity in diabetes. Gait Posture 2012, 35, 662-668. [CrossRef] [PubMed]

11. Schwebel, D.C.; Stavrinos, D.; Byington, K.W.; Davis, T.; O'Neal, E.E.; de Jong, D. Distraction and pedestrian safety: How talking on the phone, texting, and listening to music impact crossing the street. Accid. Anal. Prev. 2012, 45, 266-271. [CrossRef] [PubMed]

12. Perlmutter, S.; Cades, D.M.; Heller, M.F.; Giachetti, R.; Arndt, S.R.; Sala, J.B. Effects of mobile technology use on walking. In Proceedings of the Human Factors and Ergonomics Society 58th Annual Meeting, Chicago, IL, USA, 27-31 October 2014.

13. Byington, K.W.; Schwebel, D.C. Effects of mobile internet use on college student pedestrian injury risk. Accid. Anal. Prev. 2013, 51, 78-83. [CrossRef] [PubMed]

14. Cha, J.; Kim, H.; Park, J.; Song, C. Effects of mobile texting and gaming on gait with obstructions under different illumination levels. Phy. Ther. Rehabil. Sci. 2015, 4, 32-37. [CrossRef]

15. Nurwulan, N.; Jiang, B.C.; Iridiastadi, H. Posture and texting: Effect on balance in young adults. PLoS ONE 2015, 10, e0134230. [CrossRef] [PubMed]

16. Music, J.; Stancic, I.; Zanchi, V. Is it possible to detect mobile phone user's attention based on accelerometer measurement of gait pattern? In Proceedings of the 18th IEEE Symposium on Computers and Communications (ISCC), Split, Croatia, 7-10 July 2013. 
17. Kim, H.; Par, J.; Cha, J.; Song, C.H. Influence of mobile phone texting on gait parameters during ramp ascent and descent. Phys. Ther. Rehabil. Sci. 2014, 3, 43-48. [CrossRef]

18. Agostini, V.; Fermo, F.L.; Massazza, G.; Knaflitz, M. Does texting while walking really affect gait in young adults? J. Neuroeng. Rehabil. 2015, 12, 86. [CrossRef] [PubMed]

19. Plummer, P.; Apple, S.; Dowd, C.; Keith, E. Texting and walking: Effect of environmental setting and task prioritization on dual-task interference in healthy young adults. Gait Posture 2015, 41, 46-51. [CrossRef] [PubMed]

20. Seymour, K.M.; Higginson, C.I.; de Goede, K.M.; Bifano, M.K.; Orr, R.; Higginson, J.S. Cellular telephone dialing influences kinematic and spatiotemporal gait parameters in healthy adults. J. Mot. Behav. 2016, 24, 1-7. [CrossRef] [PubMed]

21. Kao, P.C.; Higginson, C.I.; Seymour, K.; Kamerdze, M.; Higginson, J.S. Walking stability during cell phone use in healthy adults. Gait Posture 2015, 41, 947-953. [CrossRef] [PubMed]

22. Licence, S.; Smith, R.; McGuigan, M.P.; Earnest, C.P. Gait pattern alterations during walking, texting and walking and texting during cognitive distractive tasks while negotiating common pedestrian obstacles. PLoS ONE 2015, 10, e0133281. [CrossRef] [PubMed]

23. Schabrun, S.M.; van den Hoorn, W.; Moorcroft, A.; Greenland, C.; Hodges, P.W. Texting and walking: Strategies for postural control and Implications for safety. PLoS ONE 2014, 9, e91489. [CrossRef] [PubMed]

24. Clawson, J.; Starner, T.; Kohlsdorf, D.; Quigley, D.; Gilliland, S. Texting while walking: An evaluation of mini-QWERTY text input while on-the-go. In Proceedings of the 16th international conference on Human-computer interaction with mobile devices \& services, Toronto, ON, Canada, 23-26 September 2014; pp. 339-348.

25. Hasan, S.S.; Robin, D.W.; Szurkusa, D.C.; Ashmead, D.H.; Peterson, S.W.; Shiavi, R.G. Simultaneous measurement of body center of pressure and center of gravity during upright stance. Part I: Methods. Gait Posture 1996, 4, 1-10. [CrossRef]

26. Marsh, A.P.; Geel, S.E. The effect of age on the attentional demands of postural control. Gait Posture 2000, 12, 105-113. [CrossRef]

27. Andersson, G.; Hagman, J.; Talianzadeh, R.; Svedberg, A.; Larsen, H.C. Effect of cognitive load on postural control. Brain Res. 2002, 58, 135-139. [CrossRef]

28. Huxhold, O.; Li, S.C.; Schmiedek, F.; Lindenberger, U. Dual-tasking postural control: Aging and the effects of cognitive demand in conjunction with focus of attention. Brain Res. Bull. 2006, 69, 294-305. [CrossRef] [PubMed]

29. Simoneau, E.M.; Billot, M.; Martin, A.; Perennou, D.; van Hoecke, J. Difficult memory task during postural tasks of various difficulties in young and older people: A pilot study. Clin. Neurophysiol. 2008, 119, 1158-1165. [CrossRef] [PubMed]

30. Fraizer, E.V.; Mitra, S. Methodological and interpretive issues in posture-cognition dual-tasking in upright stance. Gait Posture 2008, 27, 271-279. [CrossRef] [PubMed]

31. Palluel, E.; Nougier, V.; Olivier, I. Postural control and attentional demand during adolescence. Brain Res. 2010, 1358, 151-159. [CrossRef] [PubMed]

32. Yeh, T.T.; Boulet, J.; Cluff, T.; Balasubramaniam, R. Contributions of delayed visual feedback and cognitive task load to postural dynamics. Neurosci. Lett. 2010, 481, 173-177. [CrossRef] [PubMed]

33. Mitra, S. Postural costs of suprapostural task load. Hum. Mov. Sci. 2003, 22, 253-270. [CrossRef]

34. Huang, C.Y.; Cherng, R.J.; Hwang, I.S. Reciprocal influences on performances of a postural-suprapostural task by manipulating the level of task-load. J. Electromyogr. Kinesiol. 2010, 20, 413-319. [CrossRef] [PubMed]

35. Hsu, W.L.; Scholz, J.P. Motor abundance supports multitasking while standing. Hum. Mov. Sci. 2012, 31, 844-862. [CrossRef] [PubMed]

36. Vuillerme, N.; Nougier, V.; Teasdale, N. Effects of a reaction time task on postural control in humans. Neurosci. Lett. 2000, 291, 77-80. [CrossRef]

37. Dault, M.C.; Frank, J.S.; Allard, F. Influence of a visuo-spatial, verbal and central executive working memory task on postural control. Gait Posture 2001, 14, 110-116. [CrossRef]

38. Ehrenfried, T.; Guerraz, M.; Thilo, K.V.; Yardley, L.; Gresty, M.A. Posture and mental task performance when viewing a moving visual field. Cogn. Brain. Res. 2003, 17, 140-153. [CrossRef]

39. Toppila, E.; Forsman, P.; Pyykko, I.; Starck, J. Use of mobile phones and its acute effects on postural stability and hearing. Gait Posture 2005, 21, S16. [CrossRef] 
40. Park, S.H.; Lee, K.; Lockhart, T.; Kim, S. Effect of sound on postural stability during quiet standing. J. Neuroeng. Rehabil. 2011, 8, 67. [CrossRef] [PubMed]

41. Demura, S.; Uchiyama, M. Influence of cell phone email use on characteristics of gait. Eur. J. Sport Sci. 2009, 9, 303-309. [CrossRef]

42. Shannon, C.E. A mathematical theory of communication. ACM SIGMOBILE Mob. Comput. Commun. Rev. 2001, 5, 3-55. [CrossRef]

43. Pincus, S.M. Approximate entropy as a measure of system complexity. Proc. Natl. Acad. Sci. USA 1991, 88, 2297-2301. [CrossRef] [PubMed]

44. Lake, D.E.; Richman, J.S.; Griffin, M.P.; Moorman, J.R. Sample entropy analysis of neonatal heart rate variability. Am. J. Physiol. Regul. Integr. Comp. Physiol. 2002, 282, R789-R797. [CrossRef] [PubMed]

45. Wu, S.D.; Wu, C.W.; Lin, S.G.; Wang, C.C.; Lee, K.Y. Time series analysis using composite multiscale entropy. Entropy 2013, 15, 1069-1084. [CrossRef]

46. Ahmed, M.U.; Mandic, D.P. Multivariate multiscale entropy analysis. IEEE Signal Process. Lett. 2012, 19, 91-94. [CrossRef]

47. Sabatini, A.M. Analysis of postural sway using entropy measures of signal complexity. Med. Biol. Eng. Comp. 2000, 38, 617-624. [CrossRef]

48. Kang, H.D.; Costa, M.D.; Priplata, A.A.; Starobinets, O.V.; Goldberger, A.L.; Peng, C.K.; Kiely, D.K.; Cupples, L.A.; Lipsitz, L.A. Frailty and the degradation of complex balance dynamics during a dual-task protocol. J. Gerontol. A Biol. Sci. Med. Sci. 2009, 64, 1304-1311. [CrossRef] [PubMed]

49. Manor, B.; Costa, M.D.; Hu, K.; Newton, E.; Starobinets, O.; Kang, H.G.; Peng, C.K.; Novak, V.; Lipsitz, L.A. Physiological complexity and system adaptability: Evidence from postural control dynamics of older adults. J. Appl. Physiol. 2010, 109, 1786-1791. [CrossRef] [PubMed]

50. Gruber, A.H.; Busa, M.A.; Gorton, G.E., III; van Emmerik, R.E.A.; Masso, P.D.; Hamill, J. Time-to-contact and multiscale entropy identify differences in postural control in adolescent idiopathic scoliosis. Gait Posture 2011, 34, 13-18. [CrossRef] [PubMed]

51. Rhea, C.K.; Silver, T.A.; Hong, S.L.; Ryu, J.H.; Studenka, B.E.; Hughes, C.M.L.; Haddad, J.M. Noise and complexity in human postural control: Interpreting the different estimations of entropy. PLoS ONE 2011, 6, e17696. [CrossRef] [PubMed]

52. Huang, C.W.; Sue, P.D.; Abbod, M.F.; Jiang, B.C.; Shieh, J.S. Measuring center of pressure signals to quantify human balance using multivariate multiscale entropy by designing a force platform. Sensors 2013, 13, 10151-10166. [CrossRef] [PubMed]

53. Manor, B.; Lipsitz, L.A.; Wayne, P.M.; Peng, C.K.; Li, L. Complexity-based measures inform Tai Chi's impact on standing postural control in older adults with peripheral neuropathy. BMC Complement. Altern. Med. 2013, 13, 87. [CrossRef] [PubMed]

54. Rigoldi, C.; Cimolin, V.; Camerota, F.; Celletti, C.; Albertini, G.; Mainardi, L.; Galli, M. Measuring regularity of human postural sway using approximate entropy and sample entropy in patients with Ehlers-Danlos syndrome hypermobility type. Res. Dev. Dis. 2013, 34, 840-846. [CrossRef] [PubMed]

55. Baltich, J.; von Tscharner, V.; Zandiyeh, P.; Nigg, B.M. Quantification and reliability of center of pressure movement during balance tasks of varying difficulty. Gait Posture 2014, 40, 327-332. [CrossRef] [PubMed]

56. Chen, M.S.; Jiang, B.C. Resistance training exercise program for intervention to enhance gait function in elderly chronically ill patients: Multivariate multiscale entropy for center of pressure signal analysis. Comput. Math. Methods Med. 2014, 2014, 471356. [CrossRef] [PubMed]

57. Fournier, K.A.; Amano, S.; Radonovich, K.J.; Bleser, T.M.; Hass, C.J. Decreased dynamical complexity during quiet stance in children with Autism Spectrum Disorders. Gait Posture 2014, 39, 420-423. [CrossRef] [PubMed]

58. Pau, M.; Kim, S.; Nussbaum, M.A. Fatigue-induced balance alterations in a group of Italian career and retained firefighters. Int. J. Ind. Ergon. 2014, 44, 615-620. [CrossRef]

59. Wayne, P.M.; Gow, B.J.; Costa, M.D.; Peng, C.K.; Lipsitz, L.A.; Hausdorff, J.M.; Davis, R.B.; Walsh, J.N.; Lough, M.; Novak, V.; et al. Complexity-based measures inform effects of Tai Chi training on standing postural control: Cross-sectional and randomized trial studies. PLoS ONE 2014, 9, e114731. [CrossRef] [PubMed]

60. Yeh, J.R.; Lo, M.T.; Chang, F.L.; Hsu, L.C. Complexity of human postural control in subjects with unilateral peripheral vestibular hypofunction. Gait Posture 2014, 40, 581-586. [CrossRef] [PubMed] 
61. Decker, L.M.; Ramdani, S.; Tallon, G.; Jaussent, A.; Bernard, P.L.; Blain, H. Physical function decline and degradation of postural sway dynamics in asymptomatic sedentary postmenopausal women. J. Nutr. Health Aging 2015, 19, 348-355. [CrossRef] [PubMed]

62. Fino, P.C.; Mojdehi, A.R.; Adjerid, K.; Habibi, M.; Lockhart, T.E.; Ross, S.D. Comparing postural stability entropy analyses to differentiate fallers and non-fallers. Ann. Biomed. Eng. 2016, 44, 1636-1645. [CrossRef] [PubMed]

63. Baltich, J.; Whittaker, J.; von Tscharner, V.; Nettel-Aguirre, A.; Nigg, B.M.; Emery, C. The impact of previous knee injury on force plate and field-based measures of balance. Clin. Biomech. 2015, 30, 832-838. [CrossRef] [PubMed]

64. Costa, M.; Peng, C.K.; Goldberger, A.L.; Hausdorff, J.M. Mulriscale entropy analysis of human gait dynamics. Physica A 2003, 330, 53-60. [CrossRef]

65. Jiang, B.C.; Yang, W.H.; Shieh, J.S.; Fan, J.S.Z.; Peng, C.K. Entropy-based method for COP data analysis. Theor. Issues Ergon. Sci. 2013, 14, 227-246. [CrossRef]

66. Wei, Q.; Liu, D.H.; Wang, K.H.; Liu, Q.; Abbod, M.F.; Jiang, B.C.; Chen, K.P.; Wu, C.; Shieh, J.S. Multivariate multiscale entropy applied to center of pressure signals analysis: An effect of vibration stimulation of shoes. Entropy 2012, 14, 2157-2172. [CrossRef]

(C) 2016 by the authors; licensee MDPI, Basel, Switzerland. This article is an open access article distributed under the terms and conditions of the Creative Commons Attribution (CC-BY) license (http://creativecommons.org/licenses/by/4.0/). 